\title{
Jaarverslag prostatectomieregistratie NVU 2017
}

\author{
Henk van der Poel ${ }^{1}$ Igle-Jan de Jong · Werkgroep oncologische urologie (WOU) van de NVU
}

Published online: 19 February 2019

(c) The Author(s) 2019

\section{Samenvatting}

Het jaarverslag van de www.nvukwaliteit.nl prostatectomieregistratie laat een toename zien van het aantal geregistreerde ingrepen in 2017, terwijl het aantal ziekenhuizen dat de ingreep uitvoerde terugliep. Meer dan $80 \%$ van de prostatectomieën in de registratie werden robotgeassisteerd uitgevoerd.

Trefwoorden prostaatkanker $\cdot$ prostatectomie $\cdot$ uitkomsten $\cdot$ chirurgisch snijvlak $\cdot$ tumorstadium

\section{Annual report prostatectomy-registry Dutch Association of Urology 2017}

\begin{abstract}
The annual report of the www.nvukwaliteit.nl prostatectomy registry shows an increased number of entered prostatectomies in comparison to earlier years whereas the number of participating institutes decreased. In over $80 \%$ the prostatectomy procedures were performed robot assisted.
\end{abstract}

Keywords Prostate cancer $\cdot$ Prostatectomy $\cdot$ Outcome $\cdot$ Surgical margin $\cdot$ Tumor stage

\section{Introductie}

In 2017 werden op de website van de NVU, www. nvukwaliteit.nl, 2.413 (2016: 2.028, 19\% volumegroei) prostatectomieën geregistreerd. In 2017 groeide het aantal prostatectomieën dat robotgeassisteerd werd uitgevoerd (2017: 86\%; 2016: 82\%; 2015: 78\%) in vergelijking met de laparoscopische (2017: 6\%; 2016: 12\%; 2015: $3 \%$ ) of open (2017: 6\%; 2016: 6\%; 2015: 9\%) benadering. De prostatectomieën werden in 2017 uitgevoerd in 29 ziekenhuizen (2016 30 en 201533 ziekenhuizen resp.). In vier ziekenhuizen werden vrijwel alleen open prostatectomieën verricht, in vier vrijwel alleen laparoscopische procedures. Vanuit één ziekenhuis werden behalve 30 laparoscopische ingrepen ook vijf robotprostatectomieën gemeld. Tevens was er een ziekenhuis dat behalve vijf open prostatectomieën ook 18 robotgeassisteerde ingrepen rapporteerde. In 2016 hebben we de uitkomsten vooral gecorreleerd aan het aantal ingrepen per ziekenhuis. Gezien de case- mix hebben we dat in 2017 beperkt tot getallen rond de snijvlakstatus.

\section{Aantal ziekenhuizen}

De spreiding van de ingrepen over de verschillende ziekenhuizen was zoals aangegeven in fig. 1, 2 en 3. 16 klinieken $(55 \%)$ zat qua aantal boven het door de NVU vastgestelde minimum van 50 ingrepen per jaar. Vanuit deze 16 ziekenhuizen werd $84 \%$ van het totaal aantal prostatectomieën in Nederland geregistreerd. Naar aanleiding van een recente publicatie in het Nederlands Tijdschrift voor Geneeskunde keken we ook naar het aantal ziekenhuizen dat meer dan 100 ingrepen per jaar deed. In negen van 29 ziekenhuizen (31\%) werden meer dan 100 ingrepen ingevoerd. In deze negen ziekenhuizen werd $63 \%$ van de totale Nederlandse productie gedaan. dr. Henk van der Poel

h.vd.poel@nki.nl

1 Nederlandse Vereniging voor Urologie, Utrecht, Nederland 
Figuur 1 Aantal ingevoerde prostatectomieën per ziekenhuis in 2017

Figuur 2 Verdeling van type prostatectomie over de afgelopen vijf jaar dat werd ingevoerd in de NVU-kwaliteitsregistratie. Er werden geen perineale prostatectomieën geregistreerd
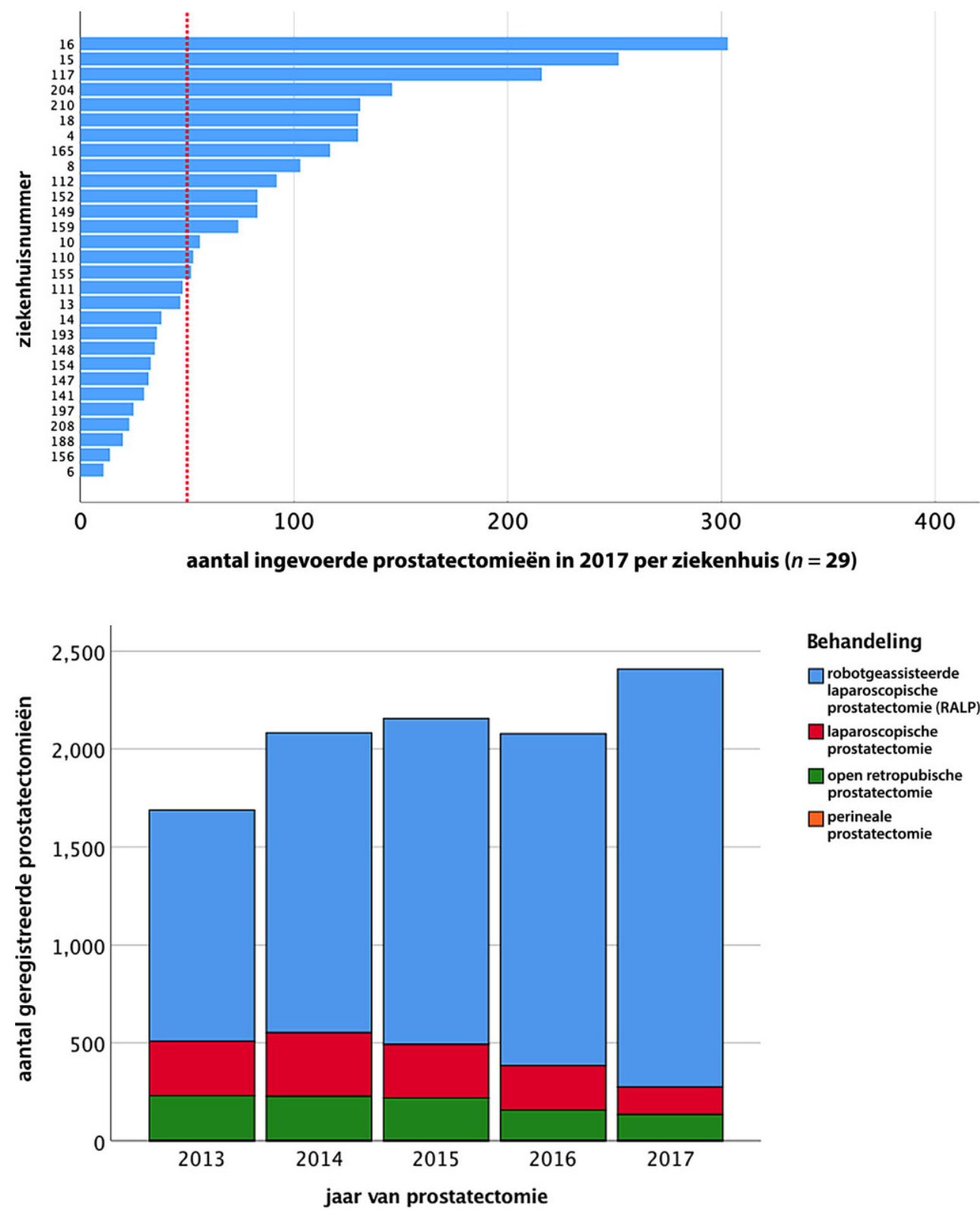

Behandeling

$\square$ robotgeassisteerde laparoscopische prostatectomie (RALP)

laparoscopische prostatectomie

$\square$ open retropubische prostatectomie

$\square$ perineale

prostatectomie

\section{Casemix}

De operatie betrof gemiddeld over alle ziekenhuizen in $37 \%$ van de gevallen een pT3-tumor. In 14 klinieken lag het percentage pT3-tumoren hoger (fig. 4).

\section{Snijvlakstatus}

Bij 30\% (2016: 32\%, 2015: 34\%) van de ingrepen werd een positief chirurgisch snijvlak geregistreerd. De geregistreerde percentages positieve snijvlakken waren hoger voor pT3-4-tumoren in vergelijking met pT2-tumoren.
Voor de verschillende ziekenhuizen zijn deze percentages weergegeven in fig. 5. In fig. 6 is te zien dat zeven ziekenhuizen zowel ten aanzien van pT2- als pT3-4-tumoren een percentage R1 had dat boven de mediaan van de gehele registratie lag. Terwijl bij zes ziekenhuizen dit percentage voor beide groepen onder de mediaan lag. Er was geen duidelijke correlatie tussen het percentage positieve snijvlakken en het aantal ingevoerde ingrepen (fig. 7). 
Figuur 3 Aantal ingevoerde ingrepen per jaar per ziekenhuis
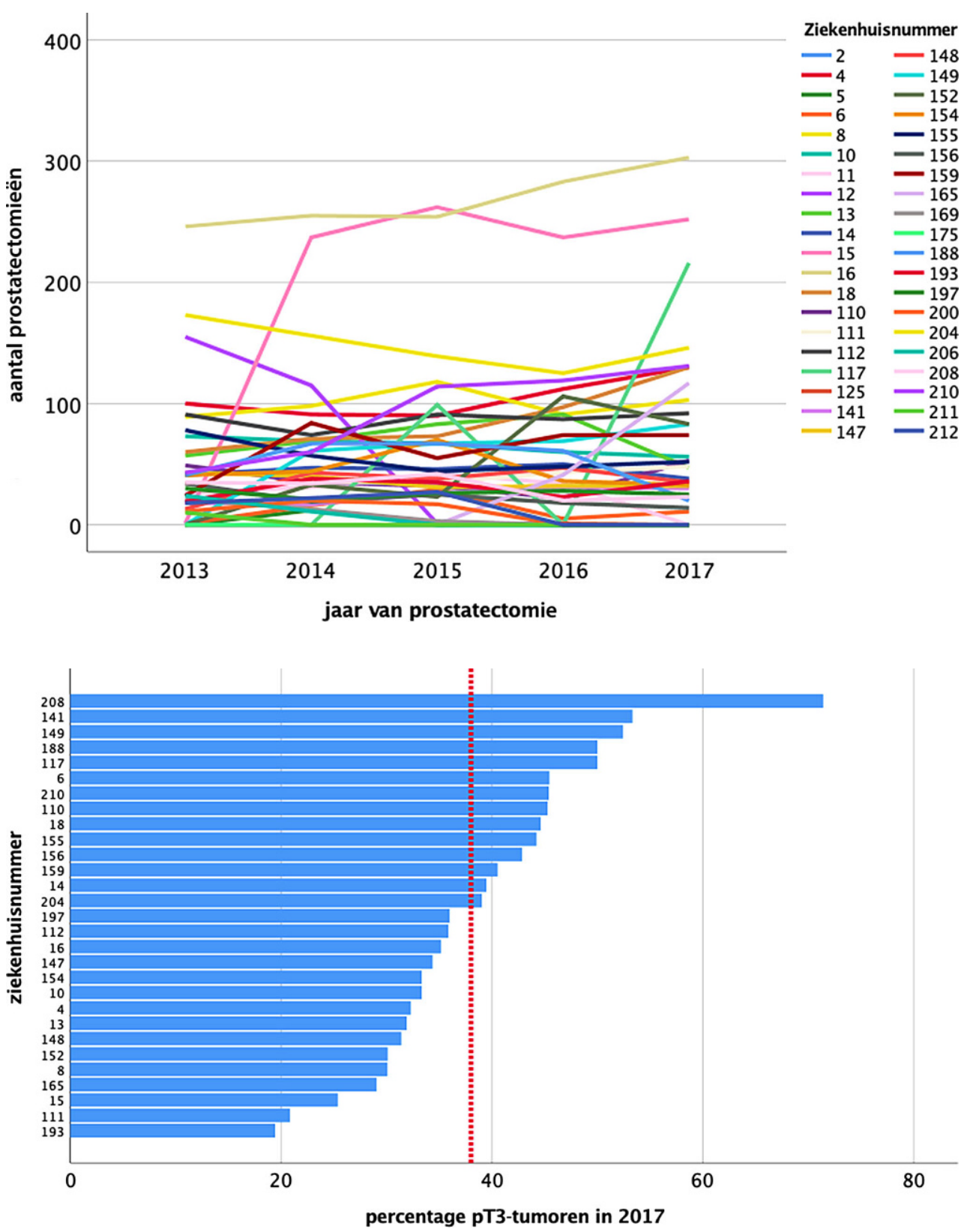

Figuur 4 Percentage pT3-tumoren per ziekenhuis. De rode lijn geeft het gemiddelde percentage van alle ziekenhuizen aan

\section{Perioperatieve uitkomsten}

Het peroperatief bloedverlies, de operatieduur en de duur van de blaaskatheterisatie per ziekenhuis is weergegeven in fig. 8, 9 en 10. Opvallend is dat in slechts twee ziekenhuizen het mediane bloedverlies meer dan $500 \mathrm{cc}$ was, dat de spreiding in de gerapporteerde operatieduur sterk varieerde tussen ziekenhuizen en dat in de meeste ziekenhuizen de katheter binnen 17 dagen verwijderd werd bij $75 \%$ van de patiënten. 
Figuur 5 Percentage positieve chirurgische snijvlakken per ziekenhuis. De rode lijn $(30,4 \%)$ is het risico op een positief snijvlak voor de gehele populatie patiënten $(n=2.413)$

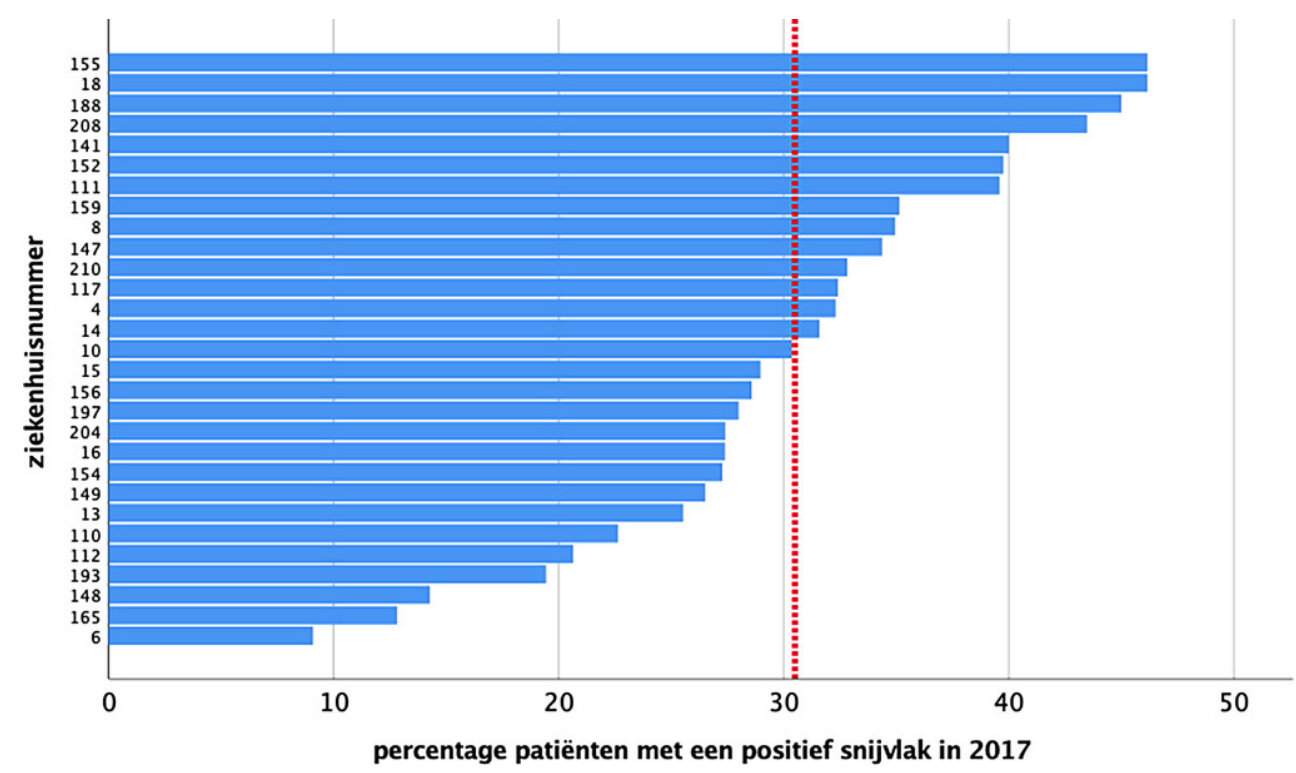


Figuur 6 Percentage positieve chirurgische snijvlakken per ziekenhuis bij patiënten met een pT2-tumor (a) of een pT3-tumor (b). In zeven ziekenhuizen (8, $10,18,111,155,156$ en 188) lagen de percentages voor zowel pT2-tumoren als pT3-tumoren boven het gemiddelde. In zes $(110,149,148,193,208,210)$ ziekenhuizen lagen die percentages onder het gemiddelde

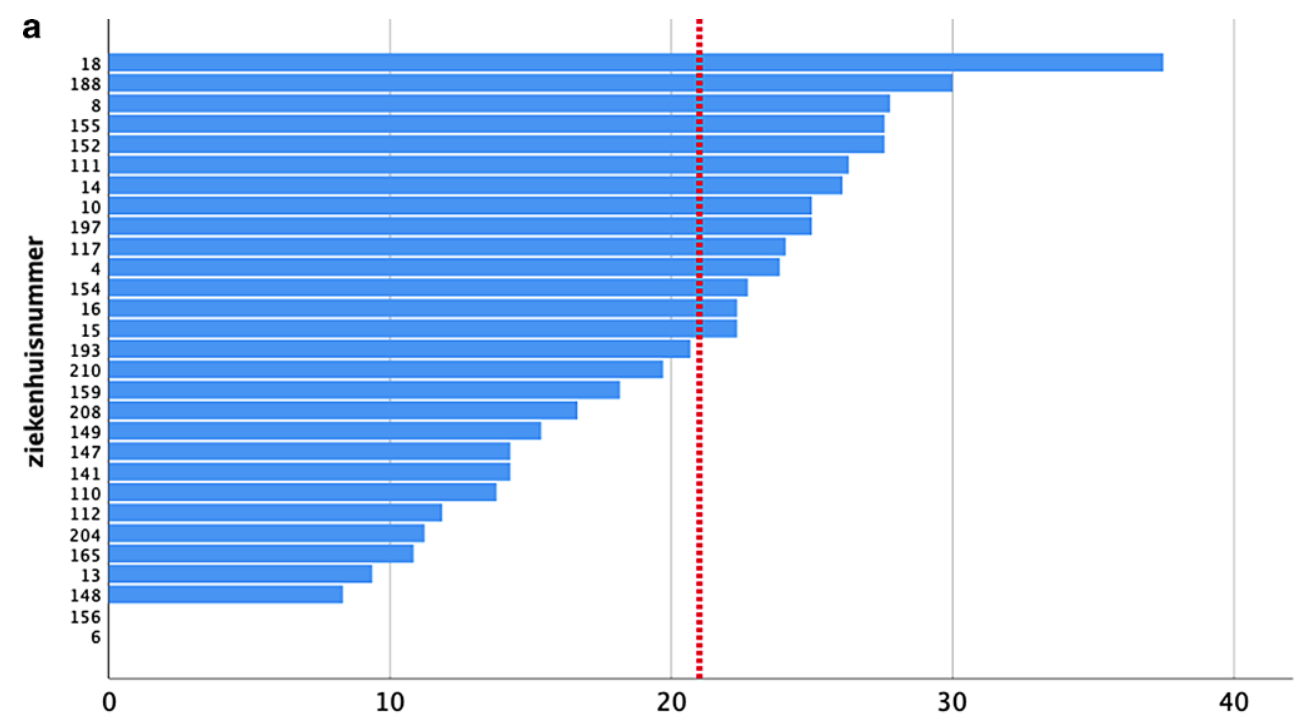

percentage positieve snijvlakken bij pT2-tumoren in 2017

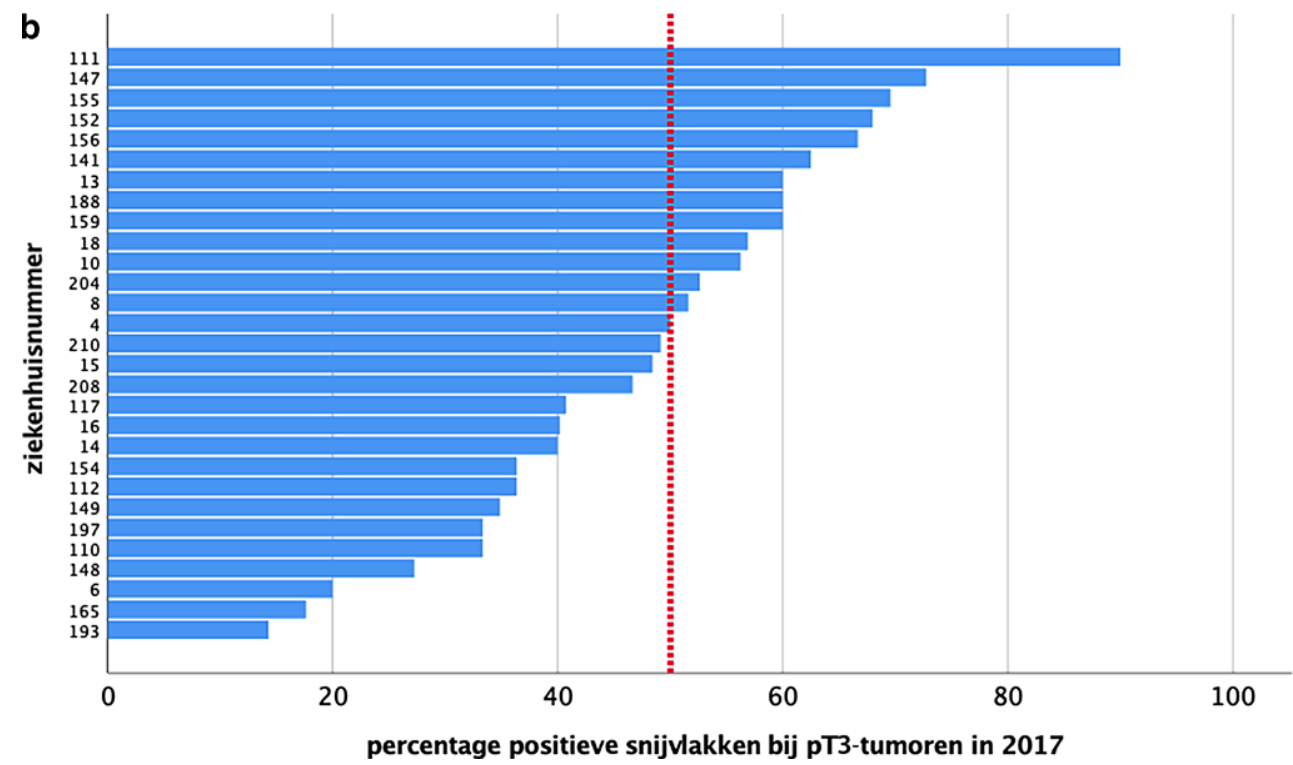


Figuur 7 Percentage positieve chirurgische snijvlakken bij pT2-tumoren (a) en pT3-4-tumoren (b) in 2017 per ziekenhuis, afgezet tegen het aantal ingevoerde ingrepen in 2017 a

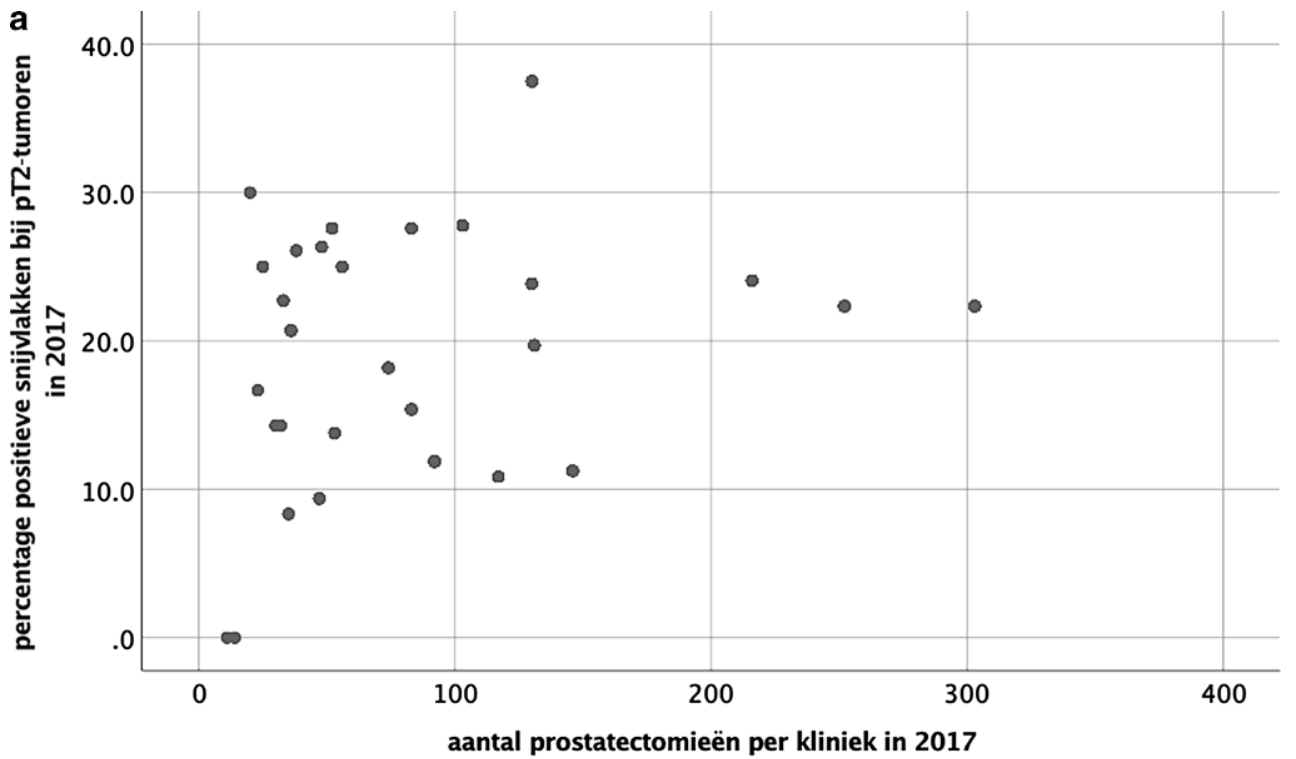

b

b

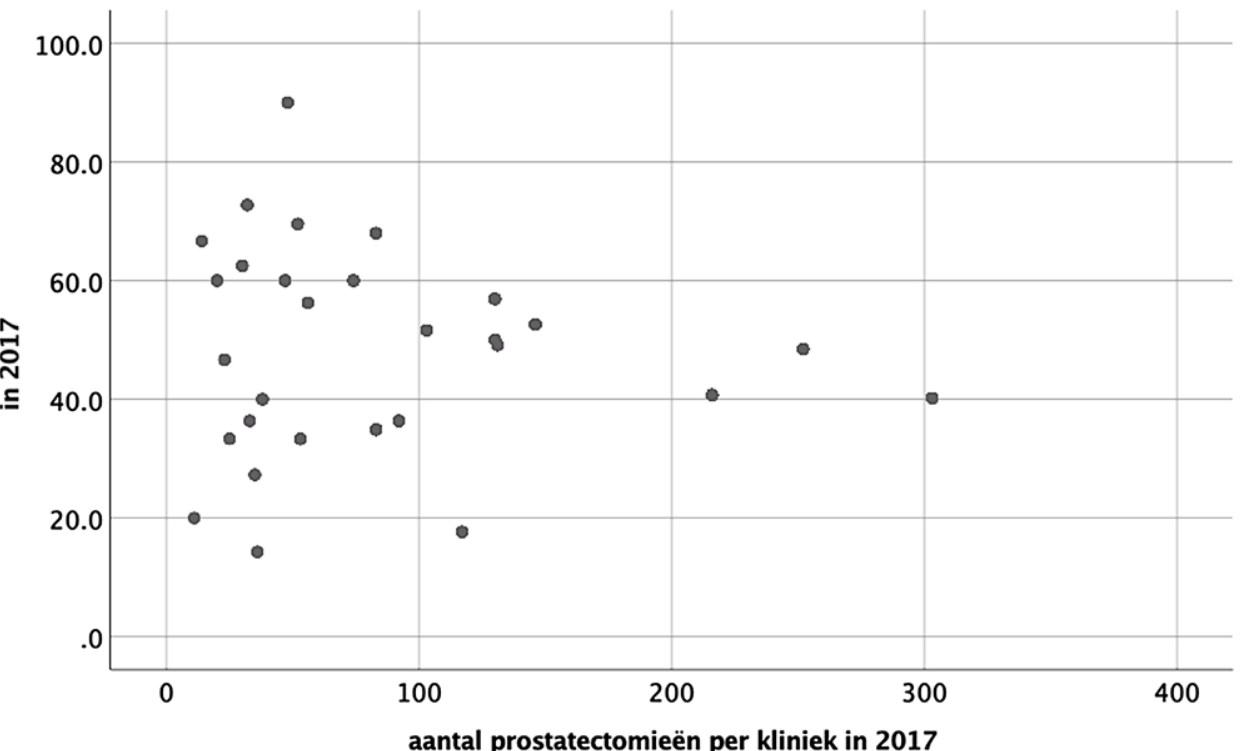


Figuur 8 Peroperatief bloedverlies per ziekenhuis

Figuur 9 Operatieduur per ziekenhuis a

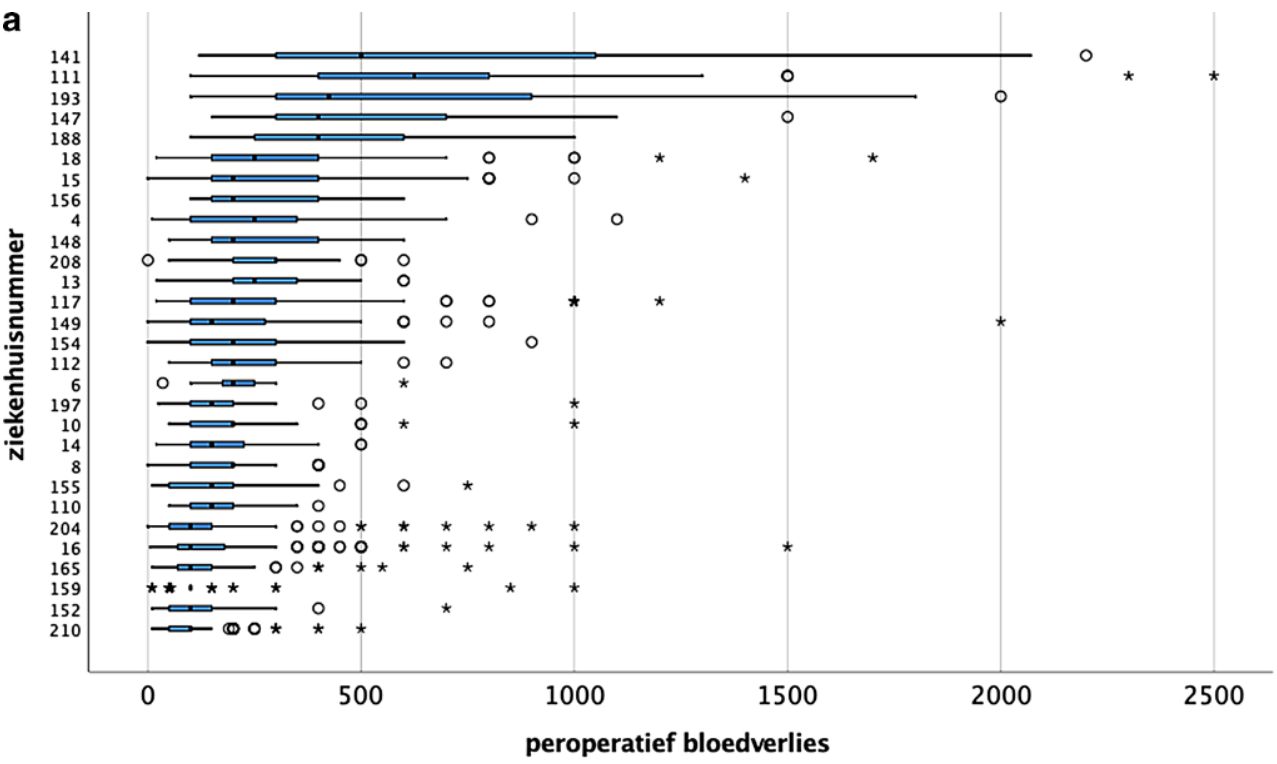

b

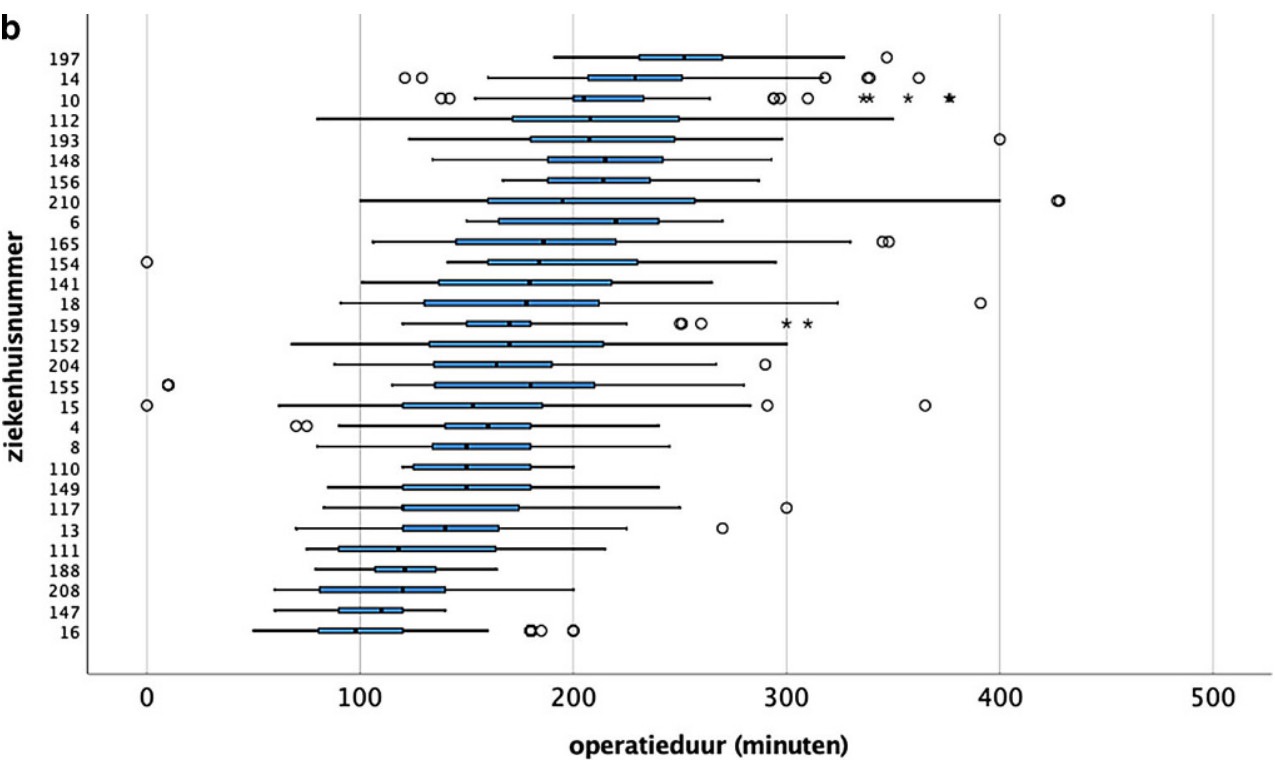


Figuur 10 Duur van de blaaskatheterisatie per ziekenhuis

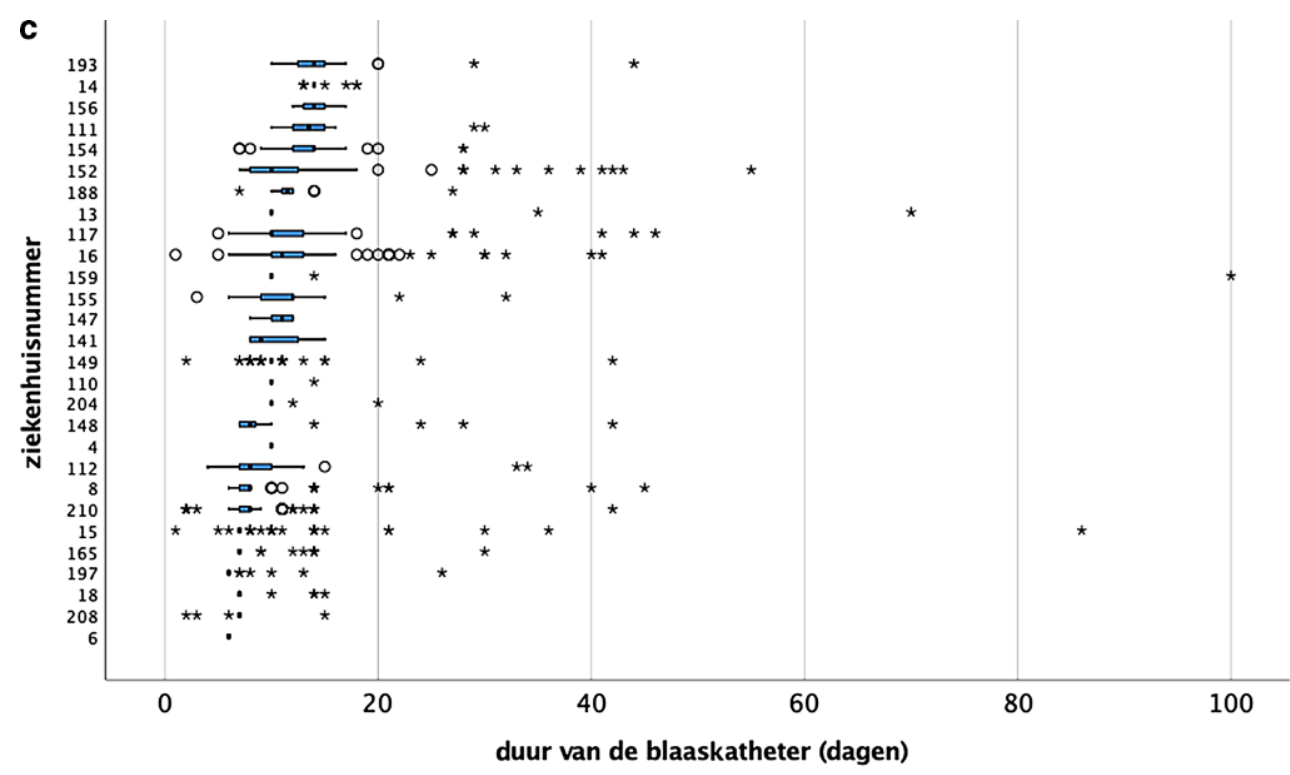

\section{Conclusies}

Naar aanleiding van de registratiedata prostatectomie kan het volgende worden geconcludeerd:

- Er is een toename in het aantal geregistreerde prostatectomieën ten opzicht van eerdere jaren.

- Tegelijkertijd is er een afname van het aantal deelnemende ziekenhuizen in de registratie.

- In $45 \%$ van de ziekenhuizen werden minder dan 50 ingrepen geregistreerd in 2017.

- In $31 \%$ van de ziekenhuizen werden meer dan 100 ingrepen geregistreerd.
Open Access This article is distributed under the terms of the Creative Commons Attribution 4.0 International License (http:// creativecommons.org/licenses/by/4.0/), which permits unrestricted use, distribution, and reproduction in any medium, provided you give appropriate credit to the original author(s) and the source, provide a link to the Creative Commons license, and indicate if changes were made.

dr. Henk van der Poel uroloog

prof. dr. Igle-Jan de Jong uroloog 